\title{
ENSINO REMOTO NA PANDEMIA: PROPOSTA DE DESIGN INSTRUCIONAL A PARTIR DE ESTILOS DE APRENDIZAGEM
}

Remote teaching in the pandemic: proposal of instructional design from learning styles

Enseñanza remota en la pandemia: propuesta de diseño instructivo a partir de estilos de aprendizaje

Received: october/2020

Accepted: november $/ 2020$

Available online: december/2020

Myriam Angélica Dornelas, Doutora em Engenharia Florestal, Instituto Federal Minas Gerais Campus Bambuí, Brasil. E-mail: myriam.dornelas@ifmg.edu.br

Cláudia Aparecida de Campos, Mestre em Agronegócio, Instituto Federal Minas Gerais - Campus Bambuí, Brasil. E-mail: claudia.campos@,ifmg.edu.br

Viviane Lima Martins, Doutora em Comunicação e Semiótica, Instituto Federal Minas Gerais Campus Avançado Arcos, Brasil E-mail: viviane.martins@,ifmg.edu.br

Resumo: O objetivo deste estudo consistiu em identificar os Estilos de Aprendizagem de alunos matriculados na disciplina Gestão e Rotinas de Recursos Humanos de um Curso Técnico em Administração de uma instituição pública federal e propor o Design Instrucional para a modalidade de ensino não presencial em função da Pandemia do Novo Coronavírus. Metodologicamente, foi realizada uma pesquisa qualitativa, de cunho descritivo a partir de um estudo de caso. Os dados foram coletados por meio de questionário fechado (N-ILS - New Index of Learning Styles). Concluiu-se 
que os principais estilos de aprendizagem da turma foram voltados para os pólos Sensitivo, Verbal, Reflexivo e Sequencial, que teve o design instrucional criado com atividades proporcionais aos Estilos identificados nessa turma.

Palavras-chave: Estilos de aprendizagem, Ensino Não Presencial, Pandemia, Novas Tecnologias da Informação e Comunicação aplicadas ao Ensino - NTIC.

\begin{abstract}
The objective of this study was to identify the Learning Styles of students enrolled in the Management and Routines of Human Resources discipline of a Technical Course in Administration of a federal public institution, and to propose the Instructional Design for the non-classroom teaching mode due to the Pandemic of the New Coronavirus. Methodologically, a qualitative, descriptive research was carried out based on a case study. Data were collected through a closed questionnaire (N-ILS - New Index of Learning Styles). It concluded that the main learning styles of the class were focused on the Sensitive, Verbal, Reflective and Sequential poles, which had the instructional design created with activities proportional to the Styles identified in this class.
\end{abstract}

Keywords: Learning styles, Non-classroom teaching, Pandemic, New Information and Communication Technologies applied to Teaching - NTIC.

Resumen: El objetivo de este estudio fue identificar los Estilos de Aprendizaje de los estudiantes inscritos en la disciplina Gestión de Recursos Humanos y Rutinas de un Curso Técnico en Administración de una institución pública federal y proponer el Diseño Instructivo para la modalidad de enseñanza no presencial debido a la Pandemia del Nuevo Coronavirus. Metodológicamente, una investigación cualitativa y descriptiva se llevó a cabo a partir de un estudio de caso. Los datos se recopilaron a través de un cuestionario cerrado (N-ILS - New Index of Learning Styles). Concluyó que los principales estilos de aprendizaje de la clase se centraban en los polos Sensible, Verbal, Reflexivo y Secuencial, que tenían el diseño instructivo creado con actividades proporcionales a los Estilos identificados en esta clase.

Palabras clave: Estilos de Aprendizaje, Educación Remota, Pandemia, Nuevas Tecnologías de la Información y la Comunicación Aplicadas a la Enseñanza - NTIC.

\title{
INTRODUÇÃO
}

A Pandemia provocada pelo novo coronavírus surpreendeu todas as comunidades do mundo, desde quando foi deflagrada. A Organização Mundial da Saúde (OMS) declarou, em 30 de janeiro de 2020, que o surto da doença constitui uma Emergência de Saúde Pública de Importância Internacional e, em 11 de março de 2020, a COVID-19 foi caracterizada pela OMS como uma pandemia. Foram confirmados no mundo 18.902.735 casos de COVID-19 (278.291 novos em relação ao dia anterior) e 709.511 mortes (6.815 novas em relação ao dia anterior) até 7 de agosto de 2020 (OPAS - ORGANIZAÇÃO PAN-AMERICANA DA SAÚDE - OPAS /OMS, 2020). 
A sociedade mundial teve de se reestruturar e se reorganizar para os desafios impostos pela nova forma de se comportar para garantir a segurança das populações perante a Pandemia. Para a área de educação não foi diferente, tendo em vista que a grande maioria das escolas teve de passar por um momento de fechamento e outras ainda se encontram nessa situação. As instituições de ensino tiveram que se adaptar e preparar-se de forma emergencial para ofertarem o ensino na modalidade não presencial.

Segundo a ONU (ORGANIZAÇÃO DAS NAÇÕES UNIDAS, 2020), em junho completou cerca de dois meses que as escolas foram fechadas em mais de 190 países, o que afetou 1,57 bilhões de crianças e jovens - 90\% da população estudantil de todo o mundo. Tais fechamentos ocorreram em rápida sucessão, como uma medida para conter o vírus da COVID-19. Com a mesma rapidez, os governos implementaram medidas para continuar o ensino por meio de plataformas, televisão e rádio, no que consistiu o experimento de maior alcance na história da educação. Contudo, quando se trata de reabrir escolas, o ritmo ainda é incerto.

A educação 4.0, até então em voga, teve de despontar do dia para a noite e muitas escolas, profissionais da educação, sejam docentes ou técnicos não estavam preparados para o cenário apresentado. Nela o conhecimento encontra-se à disposição na web, por meio de várias plataformas e programas, favorecendo uma permuta de parcerias, colaboração, atividades coletivas e partilhadas, entre outras vantagens. Segundo Kenski (2003, p. 5) "saber utilizar adequadamente essas tecnologias para fins educacionais é uma nova exigência da sociedade atual em relação ao desempenho dos educadores".

Este estudo buscou como desafio associar os possíveis estilos de aprendizagem dos educandos com o ensino na modalidade não presencial. Vieira Júnior (2019) destaca que são muitos os fatores que influenciam a relação ensino-aprendizagem como, por exemplo, os ambientais, físicos, emocionais, cognitivos, sociais etc. Muitas também são as teorias acerca desse tema 
extremamente complexo: as metodologias de ensino e aprendizagem. Talvez, um dos poucos consensos é que cada indivíduo possui um ritmo e forma característica de aprender, daí surgem os chamados Estilos de Aprendizagem, em que os discentes podem aprender melhor, uns a partir da leitura, outros pelo que ouve, alguns apreciam desenvolver trabalhos em equipes outros já são mais introspectivos, outros aprendem pela observação e visão, enquanto outros se apegam ao entendimento do todo e não das partes.

Os sujeitos dessa pesquisa foram jovens estudantes da disciplina Gestão e Rotinas de Recursos Humanos de um Curso Técnico em Administração de uma instituição pública federal que deve retomar suas atividades de ensino na modalidade não presencial. Neste sentido, o objetivo deste estudo consistiu em, a partir dos Estilos de Aprendizagem destes discentes, propor atividades e técnicas pedagógicas para o desenvolvimento dos conteúdos da disciplina na modalidade não presencial. Especificamente, o estudo apresentou um conjunto de técnicas e atividades passíveis de estimular o interesse de diferentes Estilos de Aprendizagem.

Espera-se que este trabalho contribua com docentes que ainda estejam inseguros em como conduzir ou distribuir o conteúdo a partir dessa abordagem de educação 4.0, que também pode ter surgido forçosa e inesperadamente em função da pandemia.

\section{NOVAS TECNOLOGIAS DA INFORMAÇÃO E COMUNICAÇÃO APLICADAS AO}

\section{ENSINO}

Segundo Kenski (2007), não há dúvida de que as novas tecnologias de comunicação e informação trouxeram mudanças consideráveis e positivas para a educação, porém elas precisam ser compreendidas e incorporadas pedagogicamente. Isso significa que é preciso respeitar as especificidades do ensino e da própria tecnologia para poder garantir que o seu uso, realmente, faça 
diferença. Não basta usar a televisão, tablet, computador, notebook ou celular é preciso saber usar de forma pedagogicamente correta a tecnologia escolhida.

Além disso, essas novas tecnologias possibilitam que a aprendizagem possa acontecer de forma coletiva, integrada, articulando informações e pessoas que estão em locais diferentes e que são de idade, sexo, condições físicas, áreas e níveis diferenciados de formação (KENSKI, 2003).

\section{RECURSOS EDUCACIONAIS, DESIGN INSTRUCIONAL, ATIVIDADES E TÉCNICAS VOLTADAS PARA O ENSINO NÃO PRESENCIAL}

Atualmente são vários os recursos educacionais e possibilidades para o design instrucional para o desenvolvimento das Novas Tecnologias de Comunicação e Informação aplicadas ao ensino não presencial.

Podem-se apresentar como exemplos de recursos educacionais algumas plataformas, tais como: MEC RED (referência em Recursos Educacionais Digitais, com um ambiente de busca, interação e colaboração entre professores) ${ }^{1}$; Google Sala de Aula ${ }^{2}$ (auxilia professores no gerenciamento de conteúdos educacionais, permitindo a criação, a distribuição e a avaliação de atividades de forma virtual); Formulários Google³; Redes sociais (é possível utilizar as diversas redes como suporte à educação); Murais virtuais da instituição ofertante do Curso; bibliotecas virtuais (IFMG, 2020); videoaulas promovidas pelos próprios docentes ou disponíveis em domínio público; materiais digitais de apoio tais como jogos educativos, infográficos, histórias interativas, animações, filmes, documentários, produções educacionais em TV ou streaming, livros digitais, realidade aumentada (permite interações com elementos físicos); Ambiente Virtual de Aprendizagem (AVA), dentre outros. Os Ambientes Virtuais de Aprendizagem (AVA) podem

\footnotetext{
${ }^{1}$ https://plataformaintegrada.mec.gov.br/home. Acesso em: 09 jul. 2020.

2 https://www.youtube.com/watch?v= yxiqcMDLeg. Acesso em: 09 jul. 2020.

${ }^{3}$ https://www.youtube.com/watch?v=duxAUMpLaeM. Acesso em: 09 jul. 2020.
} 
servir de apoio para a educação nas modalidades a distância e presencial, e disponibilizam recursos diversos como videoconferência, banco de recursos, fórum, bate-papo, correio, lista de discussão, blog, materiais didáticos, entre outros recursos (ALMEIDA, 2003; SANTOS, 2003; SOUZA, 2010).

Mas não basta apenas escolher a plataforma que melhor se ajusta à necessidade do docente, é importante aliar os recursos educacionais, por meio de suas plataformas e sistemas, aos projetos pedagógicos, envolvendo os conteúdos, ementas, técnicas e atividades que melhor se adequem aos objetivos de cada disciplina ou curso.

Antes de se partir diretamente para o lançamento das metodologias, técnicas ou atividades é importante que o docente elabore o design instrucional referente à disciplina que ofertará essa atividade vai além da produção de material didático, que está inserida neste processo.

Maia e Mattar (2007) destacam que o design de um curso a distância vai além do projeto visual (tipográfico) do material, requerendo que o designer (docente) planeje didaticamente o percurso do aluno no conteúdo, se será linear ou se será livre, o controle e a autonomia do aluno, o planejamento da interação no curso, acesso ao material, tecnologias utilizadas e até mesmo o custo do projeto.

Os autores apresentam outras questões, tais como: as características da audiência, a dispersão geográfica da audiência, as tecnologias disponíveis para a audiência, os objetivos dos estudantes, os objetivos e as missões da instituição de ensino, o custo que precisa ser recuperado, os custos da oferta do serviço, o ambiente político no momento para a instituição de ensino, a remuneração dos professores e a competição no mercado. Todos esses fatores entram no jogo no design de um curso a distância antes que se conduza uma análise instrucional ou de seu conteúdo (MAIA; MATTAR, 2007, p. 51).

RBPPD/BRJPD | Vol. 2 | n. 4 | p. 118-144, 2020. 
Considerando que o docente já tenha em mãos a ementa ele já pode iniciar o processo de design instrucional, a partir do que estiver estabelecido em seus objetivos (FILATRO, 2008).

Filatro (2008) divide os eventos instrucionais em quatro grandes blocos: Introdução: ativar a atenção do aluno, informar os objetivos da aprendizagem, aumentar o interesse e a motivação; Processo: Recuperar conhecimentos prévios, apresentar informações e exemplos, fornecer feedback; Conclusão: Revisar e sintetizar, transferir a aprendizagem, remotivar e encerrar; Avaliação: Avaliar a aprendizagem, fornecer feedback e complementação da aprendizagem.

Muitos são os desafios perante o ensino à distância, por isso, nessa modalidade de ensino é fundamental que se estabeleça alternativas que proporcionem um maior envolvimento dos alunos e professores no processo ensino/aprendizagem. Com relação às várias possibilidades de técnicas e metodologias voltadas para o Ensino Não Presencial é importante destacar que as atividades podem se configurar como síncronas ou assíncronas, a partir de uma classificação do tempo da comunicação.

$\mathrm{Na}$ síncrona, há o requisito que ambas as partes (emissor e receptor) estejam disponíveis ao mesmo tempo, possibilitando uma maior interação professor/aluno, em que o professor pode estimular a participação do aluno e o aluno tem condições de tirar suas dúvidas em tempo real. Na modalidade assíncrona, não há nenhuma exigência quanto ao tempo, permitindo uma maior liberdade e flexibilidade tanto para os professores, quanto para os alunos, isso dá condições para que ambos possam planejar de forma mais adequada o tempo, local e horário de trabalho e estudo.

São exemplos de comunicações assíncronas: fóruns de discussão, correio eletrônico, mensagens instantâneas, glossário, enquetes, ferramentas de disponibilização de Materiais, dentre outras. Filatro (2008) apresenta uma série de atividades que podem ser usadas no aprendizado eletrônico, como apresentado no Quadro 1.

\section{Quadro 1 - Atividades possibilitadas pelo aprendizado eletrônico}




\begin{tabular}{|l|l|}
\hline \multicolumn{1}{|c|}{ Atividade } & \multicolumn{1}{|c|}{ Descrição } \\
\hline Minute paper & $\begin{array}{l}\text { Educador (ou um aluno) propõe questões que devem ser respondidas dentro de um prazo } \\
\text { determinado (um minuto, por exemplo). }\end{array}$ \\
\hline WebQuest & $\begin{array}{l}\text { Pesquisa orientada na web, geralmente realizada em grupos. A partir da visitação } \\
\text { a sites selecionados. }\end{array}$ \\
\hline Caçada eletrônica & $\begin{array}{l}\text { Pesquisa orientada na web, em que os alunos devem localizar respostas pontuais a } \\
\text { questões ou desafios propostos. }\end{array}$ \\
\hline $\begin{array}{l}\text { Controvérsia } \\
\text { estruturada }\end{array}$ & $\begin{array}{l}\text { Debate sobre tema polêmico em que são atribuídas aos alunos posturas predefinidas (a } \\
\text { favor ou contra, por exemplo) ou papéis definidos (relator, crítico, mediador etc.). }\end{array}$ \\
\hline Debate circular & $\begin{array}{l}\text { Debate em que os alunos, um de cada vez, segundo uma ordem preestabelecida, discutem } \\
\text { uma questão comum em uma área pública, como em um fórum ou em uma sala de } \\
\text { bate-papo. }\end{array}$ \\
\hline Quebra-cabeças & $\begin{array}{l}\text { Atividade realizada em partes distribuídas como tarefas aos alunos e publicadas em área } \\
\text { coletiva para síntese e avaliação. }\end{array}$ \\
\hline Exemplos & extividade em que são apresentados vários exemplos (tais como trechos de livros, notícias \\
regras & de jornal, segmentos de vídeo, propagandas). \\
\hline Podcast & Transmissão de arquivos de áudio sobre os mais diversos conteúdos \\
\hline
\end{tabular}

Fonte: Filatro (2008, p. 50, adaptado).

Maia e Matar (2007) também apresentam um longo quadro de técnicas pedagógicas (Quadro

2), que há interseções com a autora anterior.

\section{Quadro 2 - Técnicas pedagógicas para utilização em Ensino Não Presencial}

\begin{tabular}{|c|c|}
\hline Técnica & Descrição \\
\hline Starter-wrapper & $\begin{array}{l}\text { Alguns alunos são responsáveis por iniciar as discussões e outros por finalizá-las; os } \\
\text { alunos podem desempenhar diferentes papéis. }\end{array}$ \\
\hline Discussão de artigos & $\begin{array}{l}\text { Individual ou em grupos, com a possibilidade de os alunos escolherem que artigos } \\
\text { desejam comentar. }\end{array}$ \\
\hline \begin{tabular}{l|l} 
Jigsaw \\
(quebra-cabeça)
\end{tabular} & Divisão de um texto em partes, que então são comentadas por grupos. \\
\hline $\begin{array}{l}\text { Exploração da web e } \\
\text { leituras }\end{array}$ & Avaliação e classificação de artigos \\
\hline $\begin{array}{|lr|}\begin{array}{ll}\text { Reações } \\
\text { observações }\end{array} & \text { de } \\
\text { campo } & \\
\end{array}$ & $\begin{array}{l}\text { Estágios ou experiências no trabalho que podem ser propostas em forma de } \\
\text { diários on-line. }\end{array}$ \\
\hline \begin{tabular}{|l|l|l} 
Controvérsia \\
estruturada
\end{tabular} & Os alunos devem desempenhar um papel, que podem, em geral, escolher. \\
\hline Discussões de tópicos & Alunos podem sugerir e votar nos tópicos a serem discutidos. \\
\hline \begin{tabular}{|l|l} 
Estudo de caso \\
\end{tabular} & Pode ser proposto pelo professor ou pelos alunos. \\
\hline \begin{tabular}{|l|l|}
$\begin{array}{l}\text { Quebra-gelo } \\
\text { fechamento }\end{array}$ & e \\
\end{tabular} & Apresentações dos alunos, expectativas em relação ao curso, desafios, testes. \\
\hline \begin{tabular}{|lr}
$\begin{array}{l}\text { Scavenger } \\
\text { (caçadas eletrônicas) }\end{array}$ \\
\end{tabular} & $\begin{array}{l}\text { Questões referentes a um tópico são propostas, e os sites para pesquisa, } \\
\text { predeterminados pelo professor. }\end{array}$ \\
\hline Pesquisas e votações & Pode ser discutida a opinião da maioria e da minoria. \\
\hline $\begin{array}{l}\text { Comentários } \\
\text { interativos }\end{array}$ & $\begin{array}{l}\text { Os alunos podem comentar os links sugeridos pelos colegas, o que têm em comum } \\
\text { com eles etc. }\end{array}$ \\
\hline
\end{tabular}

RBPPD/BRJPD | Vol. 2 | n. 4 | p. 118-144, 2020. 


\begin{tabular}{|l|l|}
\hline $\begin{array}{l}\text { Papel de } \\
\text { feedback para } \\
\text { colegas }\end{array}$ & $\begin{array}{l}\text { Escolha de um aluno ou amigo para comentar o trabalho e ajudar o colega durante o } \\
\text { semestre. }\end{array}$ \\
\hline $\begin{array}{l}\text { Round-robin } \\
\text { (atividades circulares) }\end{array}$ & $\begin{array}{l}\text { Histórias que são construídas ou problemas que são resolvidos parcialmente por cada } \\
\text { membro de um grupo ou da classe. }\end{array}$ \\
\hline Publicações & Publicações na web dos trabalhos dos alunos e dos grupos. \\
\hline Simpósio & Pode ser realizado no final do semestre com um expert escolhido pelos alunos. \\
\hline Brainstorm & Envolve ideias na web, para as quais pode ser criada uma lista das melhores. \\
\hline $\begin{array}{l}\text { Convidados } \\
\text { especialistas }\end{array}$ & Debates síncronos ou assíncronos. \\
\hline
\end{tabular}

Fonte: Maia e Mattar (2007, p. 57, adaptado).

Importante destacar que, como apresentado previamente, atividades assíncronas são preferenciais às síncronas, considerando o público atendido. Maia e Mattar (2007) frisam que como o Ensino Não Presencial pressupõe a separação espacial e temporal dos participantes, é natural supor que ferramentas assíncronas sejam as mais adequadas.

Além disso, o professor ainda pode lançar mão de outros recursos com vistas a otimizar o Ensino Não Presencial e uma dessas possibilidades diz respeito à compreensão sobre os possíveis estilos de aprendizagem apresentados pelos seus alunos. Ao conhecer os estilos de aprendizagem dos alunos, o professor poderá analisar a forma mais adequada de apresentar o conteúdo e atividades aos mesmos, de forma que o ensino possa ser mais efetivo e significativo, contribuindo para uma aprendizagem mais eficiente.

\section{ESTILOS DE APRENDIZAGEM}

Estilo de aprendizagem refere-se a um padrão comportamental (natural e individual) pelo qual uma pessoa possui maior facilidade em aprender (VIEIRA JÚNIOR, 2019). Para Lopes (2002) os estilos de aprendizagem seriam a maneira que o indivíduo adota na abordagem de tarefas de aprendizagem. Segundo o autor, é importante para o professor conhecer os estilos de aprendizagem dos alunos, uma vez que eles auxiliam no processo de tomada de decisão de possíveis adequações do ensino ao estilo de aprender dos alunos.

RBPPD/BRJPD | Vol. 2 | n. 4 | p. 118-144, 2020. 
O modelo de estilos de aprendizagem proposto por Felder e Silverman foi desenvolvido com base em teorias já existentes como, os tipos psicológicos de Jung, as personalidades de Myers-Briggs, a aprendizagem experimental de Kolb, estudos neuro linguísticos etc. Neste modelo cada aluno pode ser classificado de acordo com um polo de cada uma das seguintes dimensões: Percepção - o aluno é sensorial ou intuitivo; Entrada - o aluno é visual ou verbal; Processamento o aluno é ativo ou reflexivo; e Entendimento - o aluno é sequencial ou global (VIEIRA JÚNIOR, 2019). A seguir, o Quadro 3 apresentou algumas características comportamentais com base em cada polo isoladamente.

\section{Quadro 3 - Principais Características Comportamentais de cada Polo}

\begin{tabular}{|l|l|}
\hline $\begin{array}{l}\text { Sensoriais: gostam de fatos, dados e } \\
\text { experimentação. Eles preferem observar os } \\
\text { fenômenos pelos sentidos - vendo, tocando e } \\
\text { ouvindo. }\end{array}$ & $\begin{array}{l}\text { Intuitivos: eles gostam de conceitos e teorias. } \\
\text { Preferem analisar fenômenos teoricamente por } \\
\text { princípios e modelos. }\end{array}$ \\
\hline $\begin{array}{l}\text { Visuais: eles se lembram melhor daquilo que } \\
\text { veem - imagens, diagramas, filmes e e } \\
\text { demonstrações. }\end{array}$ & $\begin{array}{l}\text { Verbais: eles têm boa argumentação e preferem uma } \\
\text { explicação verbal a uma demonstração visual. }\end{array}$ \\
\hline $\begin{array}{l}\text { Ativos: eles trabalham bem em grupo e tendem } \\
\text { a ser experimentalistas. Gostam de fazer as } \\
\text { coisas por si próprios. }\end{array}$ & $\begin{array}{l}\text { Reflexivos: eles não aprendem muito em situações } \\
\text { em que não são levados a pensar sobre algo. Tendem } \\
\text { a ser bastante teóricos. }\end{array}$ \\
\hline $\begin{array}{l}\text { Sequenciais: possuem raciocínio linear durante } \\
\text { a solução de questões e se dão bem com } \\
\text { problemas que progressivamente se tornam } \\
\text { mais complexos. Normalmente entendem } \\
\text { primeiro as pequenas partes, para depois } \\
\text { compreender o todo. }\end{array}$ & $\begin{array}{l}\text { llobais: eles raciocinam por saltos intuitivos e nem } \\
\text { sempre são capazes de explicar como chegaram à } \\
\text { solução. Normalmente entendem primeiro o todo, } \\
\text { para depois compreenderem as pequenas partes. }\end{array}$ \\
\hline
\end{tabular}

Fonte: Vieira Júnior (2019, p. 2-3).

Diante dos diferentes estilos de aprendizagem apresentados, Felder e Silverman (1988) citado por Vieira Júnior (2019), possuem uma preocupação relativa à prática da sala de aula. Para os autores, a incompatibilidade entre os estilos de aprendizagem dos alunos e os estilos de ensino dos professores pode existir. A diferença entre o estilo de aprender e o de ensinar na sala de aula pode trazer reflexos negativos para os alunos, tornando-os entediados, desatentos, desanimados em relação ao curso, as disciplinas e até a si mesmos. Portanto, os autores acreditam que se os professores adaptarem seus estilos de ensino, incluindo ambos os pólos de cada dimensão, possibilitariam desenvolver um ambiente mais propício à aprendizagem para a maioria dos alunos. 


\section{METODOLOGIA}

O presente estudo tratou-se de uma pesquisa qualitativa de caráter descritivo, viabilizada pela especificidade do método de estudo de caso, já que buscou identificar e, posteriormente, descreveu os estilos de aprendizagem dos discentes de uma turma do Curso Técnico Integrado em Administração para a disciplina de Gestão e Rotinas de RH.

A pesquisa qualitativa é um fenômeno que pode ser mais bem assimilado no contexto em que ocorre e do qual é parte, devendo ser observado em uma perspectiva integrada. Para tal, o pesquisador vai a campo procurando entender o fenômeno em estudo por meio da opinião das pessoas nele envolvidas, aceitando todos os pontos de vista importantes e dessa forma diversos tipos de dados são coletados e analisados para que se entenda a ocorrência do fenômeno (GODOY, 1995).

Já a pesquisa descritiva "observa, registra, analisa e correlaciona fatos ou fenômenos (variáveis) sem manipulá-los" (CERVO; BERVIAN; SILVA, 2007, p. 61). Gil (2002, p. 42) complementa que "a pesquisa descritiva tem como objetivo primordial a descrição das características de determinada população ou fenômeno ou, então, o estabelecimento de relações entre as variáveis". A descrição específica para este estudo tratou dos resultados que foram descritos referentes aos estilos de aprendizagem dos discentes.

Visto que buscou estudar a situação específica de uma turma de alunos matriculados na disciplina Gestão e Rotinas de RH, a pesquisa também se caracterizou como um estudo de caso, que ocorre quando o pesquisador tem interesse em pesquisar uma situação singular, particular, sendo que o estudo é delimitado e tem seus contornos evidentemente determinados no desenvolver do estudo (LÜDKE; ANDRÉ, 1986). 


\section{CARACTERIZAÇÃO DO OBJETO DE ESTUDO}

A disciplina, lecionada por uma das autoras, foco do estudo é a Gestão e Rotinas de RH, com carga horária de 80 horas, ofertada anualmente na turma do segundo ano do Curso Técnico Integrado em Administração de uma instituição federal de ensino, sendo oferecida na modalidade presencial 2 aulas por semana (2 horas). A turma é formada por 40 alunos, que foram os sujeitos de pesquisa e para quem as propostas de atividades foram alinhadas.

O objetivo geral da disciplina, de acordo com o seu plano de ensino, busca compreender os principais conceitos, técnicas e processos que sustentam a Gestão de Recursos Humanos. Atualmente o Plano de Ensino da disciplina prevê as seguintes estratégias metodológicas adaptadas para esta disciplina: aulas expositivo-dialogadas, apresentação e confecção de seminários em grupo, debate e discussão sobre artigos da área e exercícios.

\section{COLETA, TRATAMENTO E ANÁLISE DOS DADOS}

A estratégia proposta para a coleta de dados que melhor atenda às diretrizes da pesquisa foi o questionário, que se trata de uma ferramenta de coleta formada por uma série ordenada de perguntas, que devem ser respondidas por escrito e sem a presença do entrevistador (MARCONI; LAKATOS, 2005).

Para o estudo foi adotado um questionário fechado, sendo este a nova versão do ILS (Index of Learning Styles - Índice de Estilos de Aprendizagem), devidamente validada e identificada por N-ILS (New Index of Learning Styles) (VIEIRA JUNIOR, 2014; GARDNER, 1995). Trata-se de um teste reduzido, de apenas 20 questões fechadas, de forma que sua extensão não seja cansativa para o respondente e implicando em respostas aleatórias.

Para realizar a coleta de dados primeiramente foi criado um Termo de Consentimento Livre e Esclarecido sobre a pesquisa que foi direcionada aos discentes matriculados na disciplina Gestão e 
Rotinas de $\mathrm{RH}$, e foi apresentado para concordância do discente antes da efetiva resposta ao questionário, tudo via e-mail.

Os discentes tiveram 15 dias para responder ao questionário elaborado no Google Formulários. Ao todo, 38 alunos responderam o questionário. Após o encerramento da coleta dos dados, os mesmos foram tabulados no Excel referente aos estilos de aprendizagem encontrados.

A partir da revisão de literatura foi realizada a análise de conteúdo das informações para a apresentação das técnicas e atividades para cada Estilo de Aprendizagem. O quadro foi proposto nos resultados e se tratou de uma contribuição com a construção do conhecimento sobre os temas e objetivou nortear o caminho de educadores que tiveram de encarar uma nova modalidade de ensino subitamente em função da Pandemia provocada pelo Novo Coronavírus.

Foi criado o design instrucional para o desenvolvimento da disciplina na modalidade de Ensino Não Presencial com propostas de atividades e técnicas variadas para atendimento de variados perfis de estilos de aprendizagem. Sendo possível, desta forma, que os temas previstos na ementa da disciplina sejam replicados para outras turmas e Cursos com o mesmo conteúdo. A próxima seção apresentou os resultados obtidos.

\section{RESULTADOS E DISCUSSÃO}

Este item apresentou os resultados obtidos a partir dos estilos de aprendizagem encontrados para os alunos respondentes, além de propor a associação de atividades e técnicas pedagógicas indicadas aos variados estilos de aprendizagem e, propor o design instrucional para o desenvolvimento da disciplina Gestão e Rotinas de Recursos Humanos, a partir dos estilos de aprendizagem encontrados, com técnicas voltadas para a modalidade de Ensino Não Presencial. 


\section{ESTILOS DE APRENDIZAGEM}

Os resultados gerais dos respondentes foram demonstrados na Tabela 1.

Tabela 1 - Estilos de aprendizagem dos respondentes

\begin{tabular}{c|c|c|c|c|c}
\hline \multirow{2}{*}{ Dimensão } & Polo/estilo & $\%$ total & $\begin{array}{c}\text { \% Preferência } \\
\text { Forte }\end{array}$ & $\begin{array}{c}\text { \% Preferência } \\
\text { Moderada }\end{array}$ & $\begin{array}{c}\text { \% Preferência } \\
\text { Leve }\end{array}$ \\
\hline \multirow{2}{*}{ Percepção } & Sensitivo & 57,9 & 5,26 & 26,32 & 26,32 \\
\cline { 2 - 6 } & Intuitivo & 42,1 & 18,42 & 7,89 & 15,79 \\
\hline \multirow{2}{*}{ Entrada } & Visual & 35,1 & 8,11 & 5,41 & 21,62 \\
\cline { 2 - 6 } & Verbal & 64,9 & 10,81 & 35,14 & 18,92 \\
\hline \multirow{2}{*}{ Processamento } & Ativo & 44,7 & 0 & 13,16 & 31,58 \\
\cline { 2 - 6 } & Reflexivo & 55,3 & 7,89 & 28,95 & 18,42 \\
\hline \multirow{2}{*}{ Entendimento } & Sequencial & 81,1 & 21,62 & 40,54 & 18,92 \\
\cline { 2 - 6 } & Global & 18,9 & 0 & 2,7 & 16,22 \\
\hline
\end{tabular}

Fonte: Dados da pesquisa (2020).

A "percepção" corresponde ao momento em que o aluno é apresentado, pela primeira vez, a um novo conteúdo e para esta dimensão observou-se que o polo Sensitivo representou a maioria dos respondentes, com 57,9\%. Os alunos sensoriais preferem observar os fenômenos pelos sentidos, seja vendo, tocando e ouvindo, enquanto os Intuitivos gostam de conceitos e teorias. Neste sentido, o resultado geral demonstra que a maioria dos respondentes gostam de fatos, dados e experimentação.

Os resultados com relação às preferências em cada polo se mostraram divididos entre a preferência moderada e leve com 26,32\% em ambas. Felder e Silverman (1988) indicam que quanto mais leve a preferência por determinado polo em cada dimensão, mais equilibrado o discente se encontra em relação às preferências de aprendizagem. Já para os discentes que se situam no polo Intuitivo, a preferência forte representou a maioria dos respondentes, com 18,42\%. Discentes cujo estilo tem preferência forte podem ter dificuldades de aprendizagem em um ambiente que não favoreça essa preferência.

A dimensão "entrada", considerada como "recepção", é definida nas primeiras assimilações e modelagens (às vezes se inicia junto com a etapa anterior) e teve o polo Verbal em destaque, 
representado por $64,9 \%$ dos respondentes. No polo Verbal os discentes têm boa argumentação e preferem uma explicação verbal a uma demonstração visual, ao passo que os Visuais, se lembram melhor daquilo que veem - imagens, diagramas, filmes e demonstrações.

A maioria dos respondentes do estilo Verbal demonstraram uma preferência moderada em sua maioria $(35,14 \%)$, enquanto a maioria para o polo Visual teve preferência leve $(21,62 \%)$. A preferência moderada indica que o aluno pode aprender mais facilmente se o ambiente de ensino favorecer esta dimensão.

Com relação à dimensão de Processamento, que corresponde àquela fase em que o aluno, mais consciente e seguro de si, faz testes, análises e inferências (a partir de exemplos, exercícios ou reflexões) resultou em 55,3\% para o polo/estilo Reflexivo e 44,7\% para o Ativo. Apesar do equilíbrio entre os respondentes o estilo Reflexivo prevaleceu. Neste estilo, não aprendem muito em situações em que não são levados a pensar sobre algo. Tendem a ser bastante teóricos, ao passo que o estilo Ativo trabalha bem em grupo e tendem a ser experimentalistas. Gostam de fazer as coisas por si próprios.

Com relação às preferências, o estilo Reflexivo teve a maioria dos respondentes com a preferência moderada $(28,95 \%)$, isto significa que os alunos terão mais facilidade em aprender se os conteúdos forem apresentados de forma mais teórica, que é a característica do estilo de aprendizagem reflexivo, visto que a preferência moderada é aquela que o aluno tende a se identificar mais com um estilo de aprendizagem específico. E os alunos que se identificaram com o estilo de aprendizagem Ativo, a maioria apresentaram preferência leve (31,58\%) a este estilo de aprendizagem, o que significa que estes alunos possuem uma maior flexibilidade em relação às duas dimensões de aprendizagem apresentadas. Assim, o professor poderá trabalhar com os conteúdos de forma que os alunos possam ser ativos, fazendo experimentações e buscando soluções para os problemas por si próprios, mas também poderão intercalar o conteúdo de forma teórica.

RBPPD/BRJPD | Vol. 2 | n. 4 | p. 118-144, 2020. 
A dimensão Entendimento, em especial no que se refere à perspectiva da aula, se aplica nas três etapas anteriores (principalmente na primeira) demonstrou que a grande maioria dos respondentes se enquadrou no estilo Sequencial $(81,1 \%)$, com a maioria $(40,54 \%)$ na preferência moderada. Este estilo indica que os alunos possuem raciocínio linear durante a solução de questões e se dão bem com problemas que progressivamente se tornam mais complexos. Normalmente entendem primeiro as pequenas partes, para depois compreender o todo.

O estilo Global representou 18,9\% dos respondentes, com a preferência leve desta modalidade pela maioria (16,22\%). Portanto, o professor poderá intercalar a forma de ensinar, ora apresentando esquemas em que o aluno consegue visualizar e entender a solução do problema e posteriormente compreender as partes que levaram à solução, e em outros momentos apresentar o conteúdo de forma sequencial para que o aluno possa compreender o todo. Isto é possível, porque a preferência leve pelo estilo de aprendizagem é aquele em que o aluno não tem uma preferência específica por algum estilo, ele é mais maleável, conseguindo dessa forma aprender em ambos os estilos de aprendizagem trabalhados.

Sendo assim, a análise geral para os estilos encontrados indica que os pólos que se sobressaíram foram Sensitivo, Verbal, Reflexivo e Sequencial. Chama a atenção que a maioria dos respondentes, quando comparando os estilos entre si, se demonstraram mais Verbais e Sequenciais, ambas com a grande maioria na preferência moderada.

\section{ATIVIDADES E TÉCNICAS PEDAGÓgICAS PARA UTILIZAÇÃO EM ENSINO NÃO PRESENCIAL INDICADAS PARA DIFERENTES ESTILOS DE APRENDIZAGEM}

Este item apresentou a indicação de possíveis atividades e técnicas pedagógicas para utilização em ensino não presencial propostas para diferentes estilos de aprendizagem. 
Sugere-se que antes de inserir qualquer atividade o docente faça a contextualização do conteúdo por texto e vídeos curtos, associando a conhecimentos prévios dos alunos.

Quadro 5 - Atividades e técnicas pedagógicas para utilização em Ensino Não Presencial indicadas para diferentes estilos de aprendizagem

\begin{tabular}{|c|c|c|}
\hline Dimensão & Estilo & \\
\hline \multirow[t]{2}{*}{$\begin{array}{l}\text { Momento } \\
\text { que o } \\
\text { aluno é } \\
\text { apresentad } \\
\text { o à } \\
\text { primeira } \\
\text { vez ao } \\
\text { conteúdo }\end{array}$} & SEN. & $\begin{array}{l}\text { Comparações entre conteúdos pelos alunos } \\
\text { Produção e apresentação de vídeos (curtos) } \\
\text { Animações sem interatividade (que funcionem sozinhas) } \\
\text { Exercícios que obriguem alguma manipulação (ou resolução) sendo descrita por } \\
\text { etapas } \\
\text { Exemplos e regras com trechos de filmes, notícias de jornal, casos reais } \\
\text { Starter-wrapper de casos reais } \\
\text { Reações a observações de campo (em forma de diários on-line) } \\
\text { Estudo de caso real por vídeo } \\
\text { Quebra-gelo e fechamento } \\
\text { Brainstorm com lista das melhores ideias práticas } \\
\text { Casos reais sobre variados assuntos } \\
\text { Uso do Chat ou o Fórum de Discussão }\end{array}$ \\
\hline & INT. & $\begin{array}{l}\text { Teorias ou novas interpretações que associem fatos e/ou demais teorias } \\
\text { Vídeo feito pelo docente com conceitos e teorias } \\
\text { Exercícios com modelagens } \\
\text { Raciocínio em exercícios sobre o assunto } \\
\text { Resolução de problemas e questões abertas } \\
\text { Exercícios com manipulação (ou resolução) com resposta oculta mostrando-a } \\
\text { apenas quando do interesse do aluno } \\
\text { Jigsaw - Quebra-cabeças } \\
\text { Exploração da web e leituras } \\
\text { Conexóes entre conteúdo e próprias experiências } \\
\text { Discussões de tópicos sobre conceitos e definições } \\
\text { Brainstorm sobre ideias abstratas } \\
\text { Convidados especialistas que debatam sobre modelagens e raciocínio lógico }\end{array}$ \\
\hline \multirow{2}{*}{$\begin{array}{l}\text { Entrada } \\
\text { "Recepçã } \\
\text { o" das } \\
\text { primeiras } \\
\text { assimilaçõ } \\
\text { es e } \\
\text { modelage } \\
\text { ns e pode } \\
\text { iniciar } \\
\text { com a } \\
\text { etapa } \\
\text { anterior }\end{array}$} & VIS. & $\begin{array}{l}\text { Diagramas, filmes, mapas mentais, imagens, fotos, fluxogramas, gráficos e } \\
\text { símbolos } \\
\text { Quebra-cabeças realizados pelos alunos com imagens relacionadas ao conteúdo } \\
\text { Jigsaw (quebra-cabeça) com imagens sobre o assunto } \\
\text { Estudo de caso com apresentações de gráficos, fluxogramas, imagens e fotos }\end{array}$ \\
\hline & VER. & $\begin{array}{l}\text { Explicação verbal } \\
\text { Conceitos textualmente e discursivamente } \\
\text { Comentários e análises textuais } \\
\text { Discussões do conteúdo Controvérsia estruturada com debates assincronamente ou } \\
\text { sincronamente } \\
\text { Debate circular em um fórum ou em uma sala de bate-papo } \\
\text { Discussão de artigos } \\
\text { Reações a observações de campo } \\
\text { Discussões de tópicos a partir vídeos curtos pelos próprios alunos } \\
\text { Quebra-gelo e fechamento } \\
\text { Comentários interativos sobre links sugeridos pelos colegas } \\
\text { Publicações na web dos trabalhos dos alunos e dos grupos }\end{array}$ \\
\hline
\end{tabular}

RBPPD/BRJPD | Vol. 2 | n. 4 | p. 118-144, 2020. 


\begin{tabular}{|c|c|c|}
\hline \multirow{2}{*}{$\begin{array}{l}\text { O aluno, } \\
\text { mais } \\
\text { consciente } \\
\text { e seguro } \\
\text { de si, faz } \\
\text { testes, } \\
\text { análises e } \\
\text { inferência } \\
\text { s (a partir } \\
\text { de } \\
\text { exemplos, } \\
\text { exercícios } \\
\text { ou } \\
\text { reflexões) }\end{array}$} & ATI. & $\begin{array}{l}\text { Atividades em grupos como construção de resumos, sínteses de tópicos e/ou } \\
\text { apresentação em grupo de ideias } \\
\text { Simulaçoses com software ou animações (computacionais) interativas que permitam } \\
\text { a manipulação } \\
\text { Busca de dados e informações (pesquisa pelos próprios alunos) com apresentação e } \\
\text { discussão prática para os problemas/assuntos encontrados } \\
\text { Exercícios com manipulação (ou resolução) } \\
\text { Minute paper } \\
\text { WebQuest } \\
\text { Caçada eletrônica } \\
\text { Controvérsia estruturada com simulações ou papéis definidos } \\
\text { Starter-wrapper } \\
\text { Exploração da web e leituras } \\
\text { Reações a observações de campo } \\
\text { Discussões de tópicos para proposição de soluções práticas } \\
\text { Papel de feedback para os colegas }\end{array}$ \\
\hline & REF. & $\begin{array}{l}\text { Paradas para reflexões onde poderá elaborar questões ou aplicações a partir do } \\
\text { conteúdo recém construído } \\
\text { Análise de conceitos por comparação } \\
\text { Questões de múltipla escolha } \\
\text { Criação de listas com palavras que representem pontos-chave } \\
\text { Respostas às atividades com discussão conceitual } \\
\text { Minute paper em design instrucional fixo } \\
\text { Quebra-cabeças realizados em partes publicadas em área coletiva para síntese e } \\
\text { avaliação } \\
\text { Discussão de artigos teóricos e comentários em Fóruns } \\
\text { Exploração da web e leituras } \\
\text { Discussões de tópicos de conceitos comparados com pequenos resumos } \\
\text { Reescrever textos com as próprias palavras }\end{array}$ \\
\hline \multirow{2}{*}{$\begin{array}{l}\text { Entendim } \\
\text { ento } \\
\text { Especial } \\
\text { no que se } \\
\text { refere à } \\
\text { perspectiv } \\
\text { a da aula } \\
\text { em } \\
\text { relação às } \\
\text { etapas } \\
\text { anteriores } \\
\text { (principal } \\
\text { mente a } \\
\text { primeira) }\end{array}$} & SEQ. & $\begin{array}{l}\text { Problemas que se tornam progressivamente mais complexos } \\
\text { Apresentação de conteúdos de forma linear } \\
\text { Explicação por etapas para depois apresentar o problema maior } \\
\text { Debate circular com ordem preestabelecida } \\
\text { Quebra-cabeças realizados em partes } \\
\text { Estudo de caso de etapas de processos } \\
\text { Round-robin (atividades circulares) } \\
\text { Convidados especialistas que apresente sequência lógica nas apresentações }\end{array}$ \\
\hline & GLO. & $\begin{array}{l}\text { Saltos intuitivos } \\
\text { Compreensão do todo primeiro e depois das pequenas partes } \\
\text { Conteúdo em grandes etapas para detalhes específicos } \\
\text { Ideal o uso de temas transversais ou de conhecimento prévio dispostos na forma de } \\
\text { conteúdo hipertextual (links) em material virtual } \\
\text { Controvérsia estruturada (temas transversais) } \\
\text { Estudo de caso a partir de conhecimentos prévios e que tenham links } \\
\text { Pesquisas e votações sobre temas globais } \\
\text { Simpósio no final do semestre com um expert escolhido pelos alunos } \\
\text { Brainstorm com lista das melhores ideias gerais } \\
\text { Solicitar a leitura de todo o material/conteúdo antes de qualquer atividade } \\
\text { Solicitar atividades que relacione os temas e assuntos com algo que lhe seja familiar }\end{array}$ \\
\hline
\end{tabular}

Fonte: Dados da pesquisa (2020). 
Na próxima seção foi detalhada a construção do design instrucional para a disciplina de Gestão e Rotinas de Recursos Humanos a partir dos estilos de aprendizagem encontrados na turma.

\section{DESIGN INSTRUCIONAL PARA A DISCIPLINA GESTÃO E ROTINAS DE RECURSOS humanos VOLTAdAS PARA O ENSINO NÃO PRESENCIAL ATENDENDO AOS ESTILOS DE APRENDIZAGEM DA TURMA}

As atividades levaram em consideração os estilos presentes na maioria dos alunos pesquisados, mas adicionando em outros momentos atividades que também representem estilos que se enquadraram em proporções menores, com vistas a atender todos os estilos presentes na turma.

A Tabela 1, no início dos resultados, mostrou a situação geral da turma que foi Sensitiva, Verbal, Reflexiva e Sequencial. O estilo Sequencial se destacou sobremaneira e ainda com uma preferência moderada. Assim, a opção por técnicas voltadas para o estilo Global foi menos proposta. Em uma segunda análise pode-se perceber o estilo Verbal com uma preferência moderada em destaque.

Os polos Ativo e Reflexivo, bem como o Sensitivo e Intuitivo se mostraram bastante equilibrados, onde o Reflexivo se destacou um pouco mais com uma preferência moderada ao passo que o Ativo teve uma maioria de preferência leve, mostrando que é melhor voltar as atividades mais para o estilo Reflexivo porque o Ativo teria menos dificuldades com atividades reflexivas do que o inverso. O estilo Sensitivo (preferência moderada e leve com mesmos valores) representou a maioria dos respondentes, mas também com pouca discrepância com relação ao polo Intuitivo, que já teve a maioria dos respondentes na preferência forte, demonstrando que atividades que atendam alunos Intuitivos deverão ser inseridas com um maior grau, quando se fala sobre as introduções sobre os conceitos.

RBPPD/BRJPD | Vol. 2 | n. 4 | p. 118-144, 2020. 
Este design proposto foi elaborado como um cronograma a ser apresentado por assuntos ao longo das 40 semanas de aulas (representado por 20 semanas do primeiro semestre e 20 semanas do segundo semestre) que representarão a disciplina de 80 horas anuais. Entende-se, desta forma, que serão promovidas atividades que representem 40 horas semestrais, ou melhor, ainda dividida em 2 horas por semana. Para aglutinar adequadamente os conteúdos as atividades propostas foram separadas por conteúdos quinzenalmente, o que gerou a divisão do conteúdo total em 20 etapas de atividades propostas.

Tentando propor uma divisão adequada de atividades de acordo com os estilos foi estipulado um percentual para cada um, onde se espera em média que a dimensão sobre o entendimento Sequencial atinja 80\% dos conteúdos (Global, 20\%). Atividades voltadas para a dimensão Entrada (assimilações) são representadas em 65\% pelo estilo Verbal e 35\% para o estilo Visual. A dimensão Processamento terá em média 55\% das atividades voltadas para o estilo Reflexivo e $45 \%$ para o Ativo. Atividades voltadas para o estilo Sensitivo representaram em média $60 \%$ e $40 \%$ para o Intuitivo para atender a dimensão de Percepção.

Quadro 6 - Distribuição das atividades voltadas para atendimento às porcentagens de estilos

\begin{tabular}{|c|c|c|c|c|c|c|c|c|}
\hline & \multicolumn{2}{|c|}{ Percepção } & \multicolumn{2}{|r|}{ Entrada } & \multicolumn{2}{|c|}{ Processamento } & \multicolumn{2}{|c|}{ Entendimento } \\
\hline & Sensitivo & Intuitivo & Visual & Verbal & Ativo & Reflexivo & \begin{tabular}{|l|} 
Sequencia \\
1
\end{tabular} & Global \\
\hline 1 & $\mathrm{X}$ & & $\mathrm{x}$ & & & $\mathrm{x}$ & & $\mathrm{x}$ \\
\hline 2 & $\mathrm{X}$ & & $\mathrm{x}$ & & $\mathrm{x}$ & & $\mathrm{x}$ & \\
\hline 3 & & $\mathrm{X}$ & & $\mathrm{X}$ & & $\mathrm{x}$ & $\mathrm{x}$ & \\
\hline 4 & & $\mathrm{x}$ & & $\mathrm{x}$ & $\mathrm{x}$ & & & $\mathrm{x}$ \\
\hline 5 & & $\mathrm{X}$ & $\mathrm{x}$ & & & $\mathrm{X}$ & $\mathrm{x}$ & \\
\hline 6 & $X$ & & & $\mathrm{X}$ & $\mathrm{x}$ & & $\mathrm{x}$ & \\
\hline 7 & & $\mathrm{X}$ & & $\mathrm{X}$ & & $\mathrm{x}$ & $\mathrm{x}$ & \\
\hline 8 & & $\mathrm{X}$ & $\mathrm{X}$ & & $\mathrm{X}$ & & $\mathrm{x}$ & \\
\hline 9 & $\mathrm{X}$ & & $\mathrm{x}$ & & $\mathrm{x}$ & & $\mathrm{x}$ & \\
\hline 10 & $\mathrm{X}$ & & & $\mathrm{X}$ & & $\mathrm{X}$ & $\mathrm{x}$ & \\
\hline 11 & $X$ & & & $\mathrm{X}$ & & $\mathrm{X}$ & $\mathrm{x}$ & \\
\hline 12 & $\mathrm{X}$ & & & $\mathrm{X}$ & & $\mathrm{x}$ & $\mathrm{x}$ & \\
\hline 13 & & $\mathrm{X}$ & $\mathrm{x}$ & & $\mathrm{x}$ & & $\mathrm{x}$ & \\
\hline 14 & $\mathrm{X}$ & & $\mathrm{x}$ & & $\mathrm{x}$ & & $\mathrm{x}$ & \\
\hline 15 & & $\mathrm{X}$ & & $\mathrm{X}$ & & $\mathrm{X}$ & $\mathrm{X}$ & \\
\hline 16 & $\mathrm{X}$ & & & $\mathrm{X}$ & & $\mathrm{x}$ & & $\mathrm{x}$ \\
\hline 17 & & $\mathrm{X}$ & & $\mathrm{x}$ & $\mathrm{X}$ & & $\mathrm{X}$ & \\
\hline
\end{tabular}

RBPPD/BRJPD | Vol. 2 | n. 4 | p. 118-144, 2020. 


\begin{tabular}{|l|l|l|l|r|r|r|r|r|}
\hline 18 & $\mathrm{X}$ & & & $\mathrm{x}$ & & $\mathrm{x}$ & $\mathrm{x}$ & \\
\hline 19 & $\mathrm{X}$ & & & $\mathrm{x}$ & & $\mathrm{x}$ & $\mathrm{x}$ & \\
\hline 20 & $\mathrm{X}$ & & & $\mathrm{x}$ & $\mathrm{x}$ & & & $\mathrm{x}$ \\
\hline $\begin{array}{l}\text { To } \\
\text { tal }\end{array}$ & 12 & 8 & 7 & 13 & 9 & 11 & 16 & 4 \\
\hline
\end{tabular}

Fonte: Dados da pesquisa (2020).

Apenas quando as atividades forem no formato síncrono foram mencionadas no Design (Planejamento) e quando não for mencionado, entende-se que as atividades propostas foram não-síncronas.

O Ambiente Virtual de Aprendizagem utilizado para esta disciplina foi o Moodle, por se tratar do sistema adotado pela instituição de ensino. A Plataforma Moodle tem se destacado por se basear na construção social a partir da colaboração entre os atores sociais (estudantes e docentes), favorecer a cooperação, a troca de materiais e conteúdos, revisões das tarefas, pesquisas, avaliação entre colegas, registro de notas e promover um processo dinâmico.

O Quadro 7 apresenta o plano geral de atividade e/ou técnicas para cada conteúdo previsto na ementa associando os estilos de aprendizagem apresentados pelos discentes desta turma, conforme já apresentado anteriormente.

Quadro 7 - Design instrucional para a disciplina Gestão e Rotinas de Recursos Humanos voltadas para o Ensino Não Presencial atendendo aos Estilos de Aprendizagem da turma

\begin{tabular}{|ll|l|l|}
\hline $\begin{array}{l}\text { N } \\
0\end{array}$ & Conteúdo & $\begin{array}{l}\text { Estil } \\
\text { o }\end{array}$ & Plano Atividades/Técnicas \\
\hline & $\begin{array}{l}\text { Planejamento de } \\
\text { Recursos } \\
\text { Humanos }\end{array}$ & $\begin{array}{l}\text { Sen. } \\
\text { Vis. } \\
\text { Ref. } \\
\text { Glo. }\end{array}$ & $\begin{array}{l}\text { Atividade síncrona via Google Meet: } \\
\text { Apresentação da ementa e Cronograma e Avaliação. Bibliografia. } \\
\text { Divisão grupos de trabalho (5 integrantes). } \\
\text { Quebra-gelo de apresentação e expectativas. } \\
\text { Mapa mental do professor sobre conteúdo geral no Planejamento de RH } \\
\text { (Caderno Didático). }\end{array}$ \\
\hline & $\begin{array}{l}\text { Recrutamento, } \\
\text { seleção, } \\
\text { admissão } \\
\text { desligamento }\end{array}$ & e & $\begin{array}{l}\text { Sen. } \\
\text { Vis. } \\
\text { Ati. } \\
\text { Seq. }\end{array}$ \\
\hline
\end{tabular}




\begin{tabular}{|c|c|c|c|}
\hline 3 & $\begin{array}{l}\text { Treinamento e } \\
\text { desenvolviment } \\
\mathrm{o}\end{array}$ & $\begin{array}{l}\text { Int. } \\
\text { Ver. } \\
\text { Ref. } \\
\text { Seq. }\end{array}$ & $\begin{array}{l}\text { Exposição por podcast pelo docente com conceitos e teorias sobre o } \\
\text { Treinamento e Desenvolvimento. } \\
\text { Alunos: Explorações da web sobre as principais técnicas de Treinamento } \\
\text { Online e quais Cursos são voltadas para a área de Administração } \\
\text { Resultado: Apresentação no Fórum de Discussão, seguindo uma ordem } \\
\text { previamente estabelecida de técnicas tradicionais e presenciais para } \\
\text { técnicas online (EaD). }\end{array}$ \\
\hline 4 & $\begin{array}{l}\text { Remuneração e } \\
\text { benefícios }\end{array}$ & $\begin{array}{l}\text { Int. } \\
\text { Ver. } \\
\text { Ati. } \\
\text { Seq. }\end{array}$ & $\begin{array}{l}\text { Podcast pelo docente com conceitos e teorias gerais sobre as formas de } \\
\text { remuneração nas organizações e os principais benefícios oferecidos pelas } \\
\text { empresas. } \\
\text { Alunos: Busca de dados e informações nos sites das empresas sobre o } \\
\text { piso salarial do Técnico em Administração, planos de carreiras e } \\
\text { benefícios, com apresentação e discussão prática para os } \\
\text { problemas/assuntos encontrados. }\end{array}$ \\
\hline 5 & $\begin{array}{l}\text { Avaliação de } \\
\text { desempenho }\end{array}$ & $\begin{array}{l}\text { Int. } \\
\text { Vis. } \\
\text { Ref. } \\
\text { Seq. }\end{array}$ & $\begin{array}{l}\text { Exploração da web e leituras de artigos sobre avaliação do desempenho. } \\
\text { Fórum de discussão: tópicos sobre conceitos comparados e definições. } \\
\text { Feedback do docente no Fórum caso alguma técnica não tenha sido } \\
\text { considerada. }\end{array}$ \\
\hline 6 & $\begin{array}{l}\text { Rotinas de } \\
\text { departamento } \\
\text { pessoal. }\end{array}$ & $\begin{array}{l}\text { Sen. } \\
\text { Ver. } \\
\text { Ati. } \\
\text { Seq. }\end{array}$ & $\begin{array}{l}\text { Vídeo curto do docente sobre rotinas do departamento de pessoal, com } \\
\text { regras do Sistema Público de Escrituração Digital (Sped), DPeSocial e } \\
\text { principais pontos da reforma trabalhista (Lei n. 13.467/2017). Alunos } \\
\text { Minute paper com questões (casos reais) relacionadas ao Sped, } \\
\text { DPeSocial e Lei 13.467/2017, nesta ordem estabelecida. }\end{array}$ \\
\hline 7 & $\begin{array}{l}\text { O subsistema de } \\
\text { departamento de } \\
\text { pessoal no } \\
\text { contexto atual }\end{array}$ & $\begin{array}{l}\text { Int. } \\
\text { Ver. } \\
\text { Ref. } \\
\text { Seq. }\end{array}$ & $\begin{array}{l}\text { Podcast feito pelo docente com conceitos e teorias sobre a Sistemática } \\
\text { do Departamento de Pessoal. Alunos: Questões de múltipla escolha } \\
\text { sobre os temas apresentados. }\end{array}$ \\
\hline 8 & $\begin{array}{l}\text { Procedimentos e } \\
\text { práticas legais: } \\
\text { contrato de } \\
\text { trabalho }\end{array}$ & $\begin{array}{l}\text { Int. } \\
\text { Vis. } \\
\text { Ati. } \\
\text { Seq. }\end{array}$ & $\begin{array}{l}\text { Vídeo do docente com conceitos e teorias sobre os Contratos de } \\
\text { Trabalho. Alunos: Simular (grupo) a criação de um contrato de trabalho, } \\
\text { onde cada contrato deverá ser disponibilizado no Fórum de discussão em } \\
\text { tópicos e os discentes terão de comentar nos tópicos que não foram } \\
\text { criados pelo seu grupo. Feedback do docente no Fórum. }\end{array}$ \\
\hline 9 & $\begin{array}{lr}\text { Carteira } & \text { de } \\
\text { Trabalho } & \text { e } \\
\text { Previdência } & \\
\text { Social } & \end{array}$ & $\begin{array}{l}\text { Sen. } \\
\text { Vis. } \\
\text { Ati. } \\
\text { Seq. }\end{array}$ & $\begin{array}{l}\text { Produção vídeos curtos (alunos) (previamente definido o grupo e o tema) } \\
\text { sobre: } 1 \text { - Processo de admissão. } 2 \text { - Atestado de Saúde Ocupacional } \\
\text { (ASO) e Registros do empregador. } 3 \text { - Programa de controle médico de } \\
\text { saúde ocupacional. } 4 \text { - Carteira de Trabalho e Previdência Social } \\
\text { (CTPS). } 5 \text { - Cadastro NIS/PIS. Cada grupo deverá postar o vídeo no } \\
\text { Fórum de discussão em tópicos. }\end{array}$ \\
\hline 10 & $\begin{array}{lr}\text { Controle } & \mathrm{e} \\
\text { registros } & \mathrm{de} \\
\text { frequência } & \end{array}$ & $\begin{array}{l}\text { Sen. } \\
\text { Ver. } \\
\text { Ref. } \\
\text { Seq. }\end{array}$ & $\begin{array}{l}\text { Vídeo curto do docente sobre Jornada de trabalho. Atividade pelos } \\
\text { alunos: responder questões de múltiplas escolhas. }\end{array}$ \\
\hline 11 & $\begin{array}{l}\text { Rotinas de folha } \\
\text { de pagamento }\end{array}$ & $\begin{array}{l}\text { Sens. } \\
\text { Ver. } \\
\text { Ref. } \\
\text { Seq. }\end{array}$ & $\begin{array}{l}\text { Atividade síncrona via Google Meet: Folha de pagamento. Atividade: } \\
\text { Questões de múltipla escolha sobre os temas. }\end{array}$ \\
\hline 12 & $\begin{array}{l}\text { Rotinas de folha } \\
\text { de pagamento }\end{array}$ & $\begin{array}{l}\text { Sen. } \\
\text { Ver. } \\
\text { Ref. } \\
\text { Seq. }\end{array}$ & $\begin{array}{l}\text { Atividade síncrona via Google Meet: Folha pagamento: Vencimentos. } \\
\text { Atividade: Questões de múltipla escolha sobre os temas. }\end{array}$ \\
\hline
\end{tabular}




\begin{tabular}{|c|c|c|c|}
\hline 13 & $\begin{array}{l}\text { Rotinas de folha } \\
\text { de pagamento }\end{array}$ & $\begin{array}{l}\text { Int. } \\
\text { Vis. } \\
\text { Ati. } \\
\text { Seq. }\end{array}$ & $\begin{array}{l}\text { Atividade síncrona via Google Meet: Descontos salariais. } \\
\text { Uso do raciocínio em lista de exercícios sobre a construção de folha de } \\
\text { pagamento para soluções práticas sobre casos específicos, com a } \\
\text { apresentação visual de cada etapa do processo da montagem da folha de } \\
\text { pagamento construída para cada caso. }\end{array}$ \\
\hline 14 & Férias & $\begin{array}{l}\text { Sen. } \\
\text { Vis. } \\
\text { Ati. } \\
\text { Seq. }\end{array}$ & $\begin{array}{l}\text { Vídeos curtos (pelos alunos - previamente definido o grupo e o tema) } \\
\text { sobre: } 1 \text { - Férias. Legislação. } 2 \text { - Férias: faltas injustificadas. } 3 \text { - Abono } \\
\text { pecuniário. } 1 / 3 \text { constitucional. Solicitação da primeira parcela do } 13^{\circ} \\
\text { salário. } 4 \text { - Aviso de férias. Recibo de férias - pagamento. } 5 \text { - Férias } \\
\text { coletivas. Férias em dobro. Incidências. }\end{array}$ \\
\hline 15 & Férias & $\begin{array}{l}\text { Int. } \\
\text { Ver. } \\
\text { Ref. } \\
\text { Seq. }\end{array}$ & $\begin{array}{l}\text { Convidados especialistas (Gestor de } \mathrm{RH}) \text { a convite de cada grupo que } \\
\text { debatam sobre modelagens de férias das empresas, sendo uma atividade } \\
\text { síncrona via Google Meet. Os alunos deverão fazer questionamentos } \\
\text { para os convidados com conceitos comparados sobre férias, por meio do } \\
\text { Debate circular com ordem preestabelecida. }\end{array}$ \\
\hline 16 & Rescisões & $\begin{array}{l}\text { Sen. } \\
\text { Ver. } \\
\text { Ref. } \\
\text { Glo. }\end{array}$ & $\begin{array}{l}\text { Vídeo curto do docente sobre os Tipos de rescisão. Atividades: } \\
\text { Starter-wrapper de casos reais de Rescisões contratuais (em grupo. Onde } \\
\text { cada grupo deverá também apresentar o resultado da busca dispostos na } \\
\text { forma de conteúdo hipertextual (links). }\end{array}$ \\
\hline 17 & Décimo terceiro & $\begin{array}{l}\text { Int. } \\
\text { Ver. } \\
\text { Ati. } \\
\text { Seq. }\end{array}$ & $\begin{array}{l}\text { Podcast curto feito pelo docente com conceitos do décimo terceiro. } \\
\text { Atividade: Resolução de problemas e questões abertas sobre o } \\
\text { pagamento de } 13^{\circ} \text { salário para proposição de soluções práticas. }\end{array}$ \\
\hline 18 & $\begin{array}{l}\text { Encargos es } \\
\text { recolhimentos }\end{array}$ & $\begin{array}{l}\text { Sen. } \\
\text { Ver. } \\
\text { Ref. } \\
\text { Seq. }\end{array}$ & $\begin{array}{l}\text { Atividade síncrona via Google Meet: Obrigações trabalhistas. Atividade: } \\
\text { Questões de múltipla escolha sobre os temas. }\end{array}$ \\
\hline 19 & $\begin{array}{lr}\text { Passivo } & \\
\text { Trabalhista } & \mathrm{e} \\
\text { Função } & \text { de } \\
\text { preposto } & \\
\end{array}$ & $\begin{array}{l}\text { Sen. } \\
\text { Ver. } \\
\text { Ref. } \\
\text { Seq. }\end{array}$ & $\begin{array}{l}\text { Discussões de tópicos (comparando os casos) sobre: } 1 \text { - Acordo coletivo. } \\
2 \text { - Convenção coletiva de trabalho. } 3 \text { - Justiça do trabalho. } 4 \text { - Passivo } \\
\text { trabalhista. } 5 \text { - Função de Preposto. }\end{array}$ \\
\hline 20 & $\begin{array}{l}\text { Fechamento } \\
\text { conteúdo }\end{array}$ & $\begin{array}{l}\text { Sen. } \\
\text { Ver. } \\
\text { Ati. } \\
\text { Glo. }\end{array}$ & $\begin{array}{l}\text { Simpósio com profissionais Gestores de RH convidados pelos grupos } \\
\text { para falar das Rotinas de RH durante o período da Pandemia (casos } \\
\text { reais). Autoavaliação pelos discentes e pelo docente sobre a avaliação } \\
\text { geral do ensino-aprendizagem-avaliação na disciplina. }\end{array}$ \\
\hline
\end{tabular}

Fonte: Dados da pesquisa (2020).

A instituição de ensino divide os Cursos Técnicos anuais com o calendário trimestral, sendo a distribuição de pontos: 30 para o primeiro trimestre, 35 para o segundo trimestre e 35 para o terceiro trimestre. Neste sentido, optou-se por distribuir a avaliação das atividades da seguinte forma. Do conteúdo 1 ao 6, representou as primeiras 12 semanas da disciplina. Ao todo foram propostas 5 atividades, e cada uma foi avaliada em 06 pontos, representando os 30 pontos distribuídos ao final do primeiro trimestre. 
O segundo trimestre representou os conteúdos de 7 a 13 (14 semanas), onde foram propostas 7 atividades, cada uma avaliada em 05 pontos, chegando-se na distribuição dos 35 pontos referentes a essa etapa. Por último, o terceiro trimestre foi representado pelos conteúdos de 14 a 20 (14 semanas), também com 7 atividades pontuadas em 5 pontos.

\section{CONCLUSÃO}

O cenário de Pandemia tem apresentado desafios de todas as ordens para diversos segmentos. A educação passará por grandes transformações neste novo cenário, seja para os docentes, como para os discentes e para as próprias instituições de ensino.

Um dos desafios impostos aos discentes é voltado para o foco nos estudos, com uma necessidade imperativa para o desenvolvimento da auto aprendizagem com eficiência para que possa fazer uso do aprendizado em sua vida pessoal e profissional no mercado de trabalho. Deverá ter uma atenção redobrada à forma como organiza o seu tempo e distribui os estudos. Espera-se que com atividades voltadas para o seu estilo de aprendizagem possa ser estimulado e motivado.

O docente deverá contribuir para que o discente desenvolva as competências, numa interrelação inseparável de conhecimentos (conteúdos), e habilidades para investigar a natureza complexa dos fenômenos do contexto da era digital. Para tanto deverá primar pela atenção ao conteúdo, mas também estabelecer a empatia e cuidado nas relações com seus alunos, promovendo incessantemente o diálogo aberto e acolhedor. Espera-se ainda que seja capaz de promover a confiança, estímulo e motivação do educando. Ao promover atividades voltadas para os estilos de aprendizagem e com um caráter mais prático poderá obter uma maior atenção dos seus alunos e, consequentemente, uma melhor aprendizagem e atendimento aos objetivos propostos em sua disciplina. O docente não deve ter receio de ousar neste cenário.

RBPPD/BRJPD | Vol. 2 | n. 4 | p. 118-144, 2020. 
Tanto educadores como educandos terão de enfrentar os obstáculos inerentes à comunicação com vistas à facilitação do processo de ensino-aprendizagem-avaliação, onde a difusão e compartilhamento do conhecimento permita que significados sejam criados e recriados e que tenham sentido e uso na vida cotidiana ou no mercado de trabalho, seja individualmente, em grupos ou em comunidades virtuais heterogêneas.

As instituições de ensino devem se preocupar com a formação e capacitação pedagógica dos docentes, propiciar a disponibilidade das NTIC tanto para docentes como para os discentes utilizarem. Além de propor um currículo flexível para que os estudantes se tornem autores de suas próprias vidas.

Tanto docentes, como discentes e as instituições de ensino deverão se atentar à organização do tempo para que todas as práticas sejam efetivas. Nesta modalidade de ensino os alunos terão que ter um maior planejamento de seus estudos adotando horários de estudos de forma a conciliar com outras atividades a serem realizadas. Da mesma forma, o professor também terá que organizar o seu tempo entre o planejamento dos conteúdos e atividades a serem postados e ministrados e principalmente ter um tempo disponível para atender aos questionamentos e dúvidas dos alunos em tempo hábil.

Finalmente, pode-se concluir que os objetivos do estudo foram atendidos ao identificar os principais estilos de aprendizagem da turma de Gestão e Rotinas de Recursos Humanos, sendo voltados para os pólos Sensitivo, Verbal, Reflexivo e Sequencial. Por último, cumpre ressaltar que o problema de pesquisa foi respondido porque, além de propor o design instrucional para o desenvolvimento desta disciplina na modalidade de Ensino Não Presencial, foi proposto também uma gama de atividades que podem ser indicadas para diferentes estilos de aprendizagem e, assim, colaborar com o desenvolvimento pedagógico de outros docentes que possam estar com 
dificuldades de alterar emergencialmente seus conteúdos para o formato Não Presencial em função da Pandemia.

\section{REFERÊNCIAS}

ALMEIDA, M. E. B. Educação a distância na internet: abordagens e contribuições dos ambientes digitais de aprendizagem. Educação e Pesquisa, São Paulo, v.29, n.2, p. 327-340, jul./dez. 2003. Disponível em https://www.scielo.br/pdf/ep/v29n2/a10v29n2.pdf. Acesso em: 09 jul. 2020.

BARDIN, L. Análise de conteúdo. Lisboa: Edições 70, 1977.

CERVO, A. L.; BERVIAN, P. A.; SILVA, R. da. Metodologia científica. 6. ed. São Paulo: Pearson Prentice Hall, 2007.

FILATRO, A. Design instrucional na prática. São Paulo: Pearson Prentice Hall, 2008. 192 p.

GARDNER, H. Inteligências múltiplas: a teoria na prática. Porto Alegre: Artmed, 1995.

GIL, A. C. Como elaborar projetos de pesquisa. 4. ed. São Paulo: Atlas, 2002.

GODOY, A. S. Pesquisa qualitativa: tipos fundamentais. Revista de Administração de Empresas, v. 35, n. 3, p. 20-29, mai./jun. 1995. Disponível em:

http://www.scielo.br/scielo.php?script=sci arttext\&pid=S0034-75901995000300004. Acesso em: 10 out. 2019.

IFMG. Ferramentas de apoio ao ensino. Disponível em https://www.ifmg.edu.br/portal/ensino/ferramentas-de-apoio-ao-ensino. Acesso em 09 jul. 2020.

KENSKI, V. M. Aprendizagem mediada pela tecnologia. Revista Diálogo Educacional, Curitiba, v. 4, n.10, p.47-56, set./dez. 2003. Disponível em

https://periodicos.pucpr.br/index.php/dialogoeducacional/article/viewFile/6419/6323. Acesso em: 23 jun. 2020.

KENSKI, V. M. Educação e tecnologias: o novo rumo da informação. Campinas Papirus Editora, 2007.

LOPES, W. M. G. ILS - inventário de estilos de aprendizagem de Felder-Soloman: investigação de sua validade em estudantes universitários de Belo Horizonte. 2002. 107f. Dissertação (Mestrado em Engenharia de Produção) - Universidade Federal de Santa Catarina, Florianópolis, 2002. Disponível em:

https://repositorio.ufsc.br/xmlui/bitstream/handle/123456789/82278/PEPS3508-D.pdf?sequence=1 \&isAllowed $=y$. Acesso em 11 mai. 2020.

LÜDKE, M.; ANDRÉ, M. E. D. A. Pesquisa em educação: abordagens qualitativas. São Paulo: EPU, 1986. Disponível em: 
https://moodle.ufsc.br/pluginfile.php/2431625/mod resource/content $/ 1 /$ Pesquisa $\% 20 \mathrm{em} \% 20$ Educa \%C3\%A7\%C3\%A30\%20Abordagens\%20Qualitativas\%20vf.pdf. Acesso em: 10 out. 2019.

MAIA, C.; MATTAR, J.. ABC da EaD: A educação a distância hoje. São Paulo: Pearson Prentice Hall, 2007. 156 p.

MARCONI, M. de A.; LAKATOS, E. M. Fundamentos da metodologia científica. 7. ed. São Paulo: Atlas, 2005.

ONU - ORGANIZAÇÃO DAS NAÇÕES UNIDAS. Reabrir as escolas: quando, onde e como? Disponível em https://nacoesunidas.org/artigo-reabrir-as-escolas-quando-onde-e-como/. Acesso em 10 jul. 2020.

OPAS - ORGANIZAÇÃO PAN-AMERICANA DA SAÚDE / OMS - ORGANIZAÇÃO MUNDIAL DA SAÚDE. Folha informativa - COVID-19 (doença causada pelo novo coronavírus): principais informações. Atualizada em 07 Jul. 2020. Disponível em https://www.paho.org/bra/index.php?option $=$ com content\&view $=$ article\&id $=6101$ :covid19\&Itemid $\underline{=875}$. Acesso em: 10 jul. 2020.

SANTOS, E. O. Ambientes virtuais de aprendizagem: por autorias livres, plurais e gratuitas. Revista FAEBA, v.12, n. 18. 2003. Disponível em: http://www.comunidadesvirtuais.pro.br/hipertexto/home/ava.pdf. Acesso em: 09 jul. 2020.

SOUZA, G. V. Ambiente computacional para auxiliar na Aprendizagem do surdo. 2010. 100f. Dissertação (Mestrado Integrado Profissional em Computação Aplicada) - Universidade Estadual do Ceará e Instituto Federal Educação Ciência e Tecnologia do Ceará, Fortaleza, 2010. Disponível em: http://www.uece.br/mpcomp/index.php/arquivos/doc_download/218-dissertacao-55. Acesso em 09 jul. 2020.

VIEIRA JUNIOR, N. Construção e validação de um novo índice de estilos de aprendizagem. In: MCTI; UNESCO; CNPq. (Org.). Educação para a ciência. Brasília: MCTI, 2014.

VIEIRA JÚNIOR, N. Metodologias de Ensino e Aprendizagem. Arcos: IFMG Arcos Pós-Graduação em Docência, 2019. 